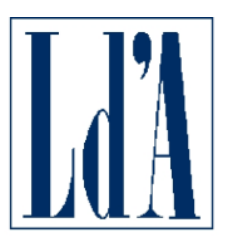

CENTRO STUDI LUCA D'AGLIANO

WWW.DAGLIANO.UNIMI.IT

CENTRO STUDI LUCA D'AGLIANO

DEVELOPMENT STUDIES WORKING PAPERS

N. 375

November 2014

Shedding Light on Inventors' Returns to Patents

Domenico Depalo *

Sabrina Di Addario *

* Bank of Italy 


\title{
Shedding Light on Inventors' Returns to Patents
}

\author{
Domenico Depalo $\quad$ Sabrina Di Addario *
}

November 10, 2014

\begin{abstract}
We estimate individual returns to patents using a unique longitudinal administrative dataset on patents and earnings, following individuals and firms for 20 years (1987-2006). We find that inventors' wages steadily increase before patent applications are submitted to the European Patent Office, reach a peak around the time of submission and then decrease again. We also find that the applications that will eventually lead to a granted patent receive a greater wage increase than those that will not. Finally, we use an event study framework to distinguish among inventor-types and we find that the "star-inventors" (the employees submitting at least three times in their life) receive a lasting wage premium, while the employees with one or two submissions stop receiving the premium after the application date, in line with the "unobserved ability" literature.
\end{abstract}

JEL classification: O31, J31.

Keywords: Patents; Wages; Incentives; Inventors; Performance pay; Return.

\footnotetext{
${ }^{*}$ Domenico Depalo and Sabrina Di Addario, Bank of Italy. We are grateful to David Card, Ernesto Dal Bo, Patrick Kline, Jesse Rothstein, Steven Tadelis, Eliana Viviano and Noam Yuchtman for their excellent comments. We also thank INPS for having provided the employer-employee matched dataset and the team that helped us matching it to Patstat (Carla Bertozzi, Michela Carlana, Fabrizio Marini, Carlo Menon, Giovanna Marcolongo, Michel Serafinelli and Gian Maria Tomat). Finally, we thank the participants to: the Labor Lunch Seminars and the Innovation Seminars at the University of Berkeley (respectively, November 16 and November 21, 2012, Berkeley), and the Bank of Italy's Seminar (March 20, 2013, Rome). Some of the work for this paper was undertaken while the authors were visiting the Center for Labor Economics and the Institute for Research on Labor and Employment at the University of Berkeley; they thank the Center and I.R.L.E for their hospitality. All the routines will be available at the webpages: http://sites.google.com/site/domdepalo/ and http://sites.google.com/site/sabrinadiaddario/ The views expressed herein are those of the authors and not necessarily those of the Bank of Italy. Corresponding author: Sabrina Di Addario, Bank of Italy, Rome Branch, Economic Research Unit, Via XX Settembre, 97/E - 00187 Rome, Tel.: +39-06-4792 3458, Fax: +39-06-4792 5626, e-mail: sabrina.diaddario@bancaditalia.it
} 


\section{Introduction}

While the benefits firms derive from patenting have been analyzed in the literature (see, for instance, Hall, Jaffe, and Trajtenberg (2000); Geroski, Machin and Van Reenen (1993); Balasubramanian and Sivadasan, 2011), very little is known about the incentives for workers to invent. Understanding inventors' motivation may be important to increase firms' innovation rates and, ultimately, the micro-foundations of countries' technological progress. Although monetary incentives may not be the primary source of motivation for pure researchers, who are perhaps also spurred by a passion for research or a search for fame, wage premia acknowledge good work and may raise the motivation of some inventor types. However, in most countries employees are requested to cede all the property rights of their inventions to their employers, in which case patenting does not necessarily provide inventors with direct monetary compensation. In fact, informal talks with some inventors and the (scant) existing empirical evidence indicate that, on average, workers do obtain a premium after an invention. Van Reenen (1996) finds that a major innovation raises firms' aggregate wages by 2 percent 4 years after commercialization, on the basis of a sample of almost 600 firms observed over 6 years. Toivanen and Väänänen (2012) estimate inventors' returns to patents by using individual panel data on almost 2,000 Finnish inventors whose inventions were patented in the U.S. over a period of 9 years $(1991-1999)$, and find that inventors obtain a $1-2$ percent premium in the year the firm is granted a patent, or a $4-5$ percent wage increase 4-6 years after, depending on the model specification used.

The objective of this paper is to verify empirically whether and how inventors are rewarded for their inventions. We use a unique longitudinal dataset on patents and earnings, following individuals and firms for 20 years $(1987$ - 2006). In particular, we build a new concordance between the European Patent Office (EPO) database on patents (Patstat) and the Italian employer-employee matched dataset on individual wages from the Italian Social Security Institute (INPS). To the best of our knowledge we are the first to link the EPO database to individual inventors' wages, demographic and job characteristics. Our linking procedure, which is based on an exact matching of inventors' names, location and employer, enables us to match a higher number of inventors than 
we would have obtained had we used only firms' names, which is the standard matching procedure with these data.

Like in Toivanen's and Väänänen's (2012) pioneer work, we estimate individual returns to patents with a Mincerian wage function augmented with patent application indicators. We add to the previous literature in many respects. First, the longer time-dimension and the size of our panel (more than 13,500 inventors followed for 20 years) enables us to study more precisely the dynamics of inventors' earnings. In particular, by using 19 lags and leads of the application filing date (our patent variable) we are able to verify empirically whether the data are more consistent with the theories of "unobserved effort", "unobserved ability" or "intrinsic motivation", predicting, respectively, that firms reward inventors with a one-off bonus at the time of a patent submission, with a permanent wage increase, or do not reward them at all. Second, while in our regressions we always include worker-fixed effects, we test whether our results persist after controlling for both individuals' and firms' unobserved heterogeneity. Third (and most importantly), using an event study framework we test whether firms' patenting compensation policies depend on the inventor type, which we define on the basis of the number of patent applications each employee is able to submit in his/her working life. In particular, the relevant distinction is between the employees who invent just once or twice, possibly because of luck, and the "star-inventors", the workers submitting at least three times in our observational period.

Results show that inventors' wages start increasing a few years before patent applications are submitted to the EPO, peak in the year preceding their filing (about 1 percent each year), and then decrease again. We take the fact that earnings peak at $t-1$ instead of at $t$ as a bureaucratic delay between the time the invention really takes place and the time when the firm submits the application. In particular, inventors receive a 3.5 percent premium the year before submission, a result consistent with Toivanen and Väänänen (2012), who obtain a 1.6 percent premium at the time the patent is granted. We also test whether there is a difference between the applications that will eventually lead to a grant and those that will not, and we find that the inventors who will actually obtain a grant earn a 2 percent higher premium than those who will not (although the patterns are similar in the two cases). Finally, the event-study results show that the premia 
received by the employees with one or two submissions do not persist after the application date. In contrast, firms are willing to provide a permanent wage increase after the third submission. For instance, inventors earning the average wage of 40,000 euros at time $t-8$ and submitting just once in their life will receive 44, 200 euros when they complete the invention (at time $t$-1), 40, 400 euros at time $t+2$ and will return to their initial wage $3 / 4$ years after submission. Conversely, the earnings of an inventor with the same characteristics but submitting at least 5 times will keep growing after the fifth patent completion, up to 44,300 euros at time t-1,44,900 euros at time $t+2$ and 46,300 euros at time $t+5$. The increase is monotonic in the number of submissions. Our results are robust to different sample selections and to various estimators, including a double fixed-effect estimator, which makes our estimates consistent even in the presence of omitted time-invariant characteristics pertaining to individuals and/or firms.

Summarizing, the average wage setting scheme for patenting inventors in Italy is the following. Employers pay inventors a small and increasing premium during the time they undertake research, either to avoid that they leave the firm or to ensure that they keep putting enough effort each year until the patent submission is completed. Firms are willing to provide a permanent premium, in line with the unobserved ability theories, only to the employees who have proven to be high-ability types (i.e., the inventors who contributed to at least three patent submissions). In contrast, the premia of the workers who have invented just once or twice do not persist after the application date, probably because the employer is still not sure of whether the invention was due to their ability or just to luck.

The paper is structured as follows. The next section presents the related literature, Section 3 the dataset, the variables and the descriptive statistics. Section 4 reports the empirical model and discusses the estimation results. Finally, the last section concludes.

\section{Related literature}

The majority of the literature analyzes the impact of patents at the national, sectoral, or firm level; very few studies examine the benefits accruing to inventors, largely because of lack of data. 
At the country level, Eaton and Kortum (1999) find that patents raise R\&D and growth. Studies at the firm level show that patents increase market value (Griliches, Pakes and Hall (1986) and Hall, Jaffe, and Trajtenberg, 2000), profitability (Geroski, Machin and Van Reenen, 1993), R\&D (Arora, Ceccagnoli, and Cohen, 2008), and are positively correlated to companies' size, skill and capital intensity, labor productivity and TFP (Balasubramanian and Sivadasan, 2011). In contrast, Boldrin and Levine (2013) argue that the evidence in favor of any effect of patents on innovation or productivity is not conclusive; in fact, the general equilibrium impact on innovation might even be negative (for instance, because the monopoly power generated by previous patents raises entry costs and thus reduces the number of innovating firms).

The scantness of data on inventors' earnings has limited the research on returns to patents. Indeed, most studies link patent data to information at the firm level. For instance, Van Reenen (1996) finds that firms' average wages increase by 2 percent 4 years after the commercialization of a major innovation, using aggregate earnings data on 600 companies. Linking compensation survey data to the NBER patent information from the US Patent and Trademark Office (USPTO), Lerner and Wulf (2007) obtain that offering long-term incentives (i.e., stock options) to corporate R\&D heads has a positive effect on firm's patent citations, awards and original patents. Toivanen and Väänänen (2012) use individual-level data, linking a Finnish employer-employee matched dataset to the NBER patent grant data over the period 1991 - 1999. They show that, after controlling for individuals' unobservable heterogeneity, inventors obtain a $1-2$ percent premium in the year the firm is granted a patent, or a $4-5$ percent wage increase $4-6$ years after (depending on the model specification used). However, in their case the existence of a premium is somewhat expected because in Finland firms are obliged by law to reward the employees who take out a patent.

From a theoretical point of view it is not obvious that patents produce any individual return, since in most countries applicant firms entirely retain the inventions' property rights and are not legally obliged to reward their employees for patenting (except for "occasional inventions"). Thus, if, how and why firms choose to reward inventors even if they do not have to is an interesting issue, hardly examined before.

The agency literature is a useful framework to analyze individuals' incentives to patent: firms 
(principals) have to decide whether to hire potential inventors (agents) without knowing their ability and/or willingness to exert effort, and inventors have to choose a level of research activity without knowing whether they will be successful. Although employers cannot observe inventors' innate characteristics or behavior, they can design compensation contracts that induce employees to either reveal their type or to behave in the interest of the firm. Contracts on patentable inventions would not be difficult to design because patents are observable outcomes, unlike most of workers' output. In Italy such contracts would be firm-specific, as the Italian law does not establish whether companies should reward the employees who contribute to an invention (unlike the Finnish law, for instance). Patent premia could potentially be in the form of piece rates, bonuses, salary revisions, deferred compensation, promotions, as well as options and profit-sharing. We will be able to assess only whether inventors' earnings increase, on average, in proximity of an invention submission and whether this increase is temporary or permanent To have a theoretical framework for interpreting our empirical results, in this section we will broadly classify theories according to whether they predict permanent returns to patents, one-off bonuses or no premia at all.

\section{A) Unobserved ability and permanent wage premia.}

Models of adverse selection, whereby firms cannot access important information on inventors' permanent characteristics (e.g. ability, productivity, basic skills, or competence) are best suited to explain the existence of permanent returns to patents. In an efficiency-wages framework, employers might be willing to offer inventors greater than market-clearing wages for two main reasons.

First, to select the best workers (Lazear, 1986). The idea is that the most able employees benefit more from greater compensation contracts linked to output than the least able ones, thus employers are able to select the best inventors by offering higher pay-for-performance contracts. One of the first systems put in place in history to attract the best inventors was created in the Venetian Republic in 1474 by assigning artisans exclusive rights on their inventions (Moser, 2013).

Second, to minimize turnover costs. Since the cost of losing an inventor could be particularly high to the firm, employers might offer economic-rents to retain the key-workers in their company.

\footnotetext{
${ }^{1}$ We cannot estimate the effect of profit-sharing because our data does not include information on workers' earnings from capital. However, this is not a severe limitation of our data, because the majority of the premia are in the form of labor earning increases.
} 
To have a better understanding of the results that we will present in this paper it is useful to distinguish between two phases: (a) the period during which inventors are engaged in the research process leading to a patent application (which might take a long time), and (b) the period following the patent submission.

(a) Even though initially employers cannot observe inventors' innate ability, after a worker is hired firms gradually update their information set by observing the employee's output realizations over time. During the research time leading to a patent application current employers are more able to learn about the worker's ability than prospective firms ("private learning"; Farber and Gibbons, 1996). Although in this period rival firms cannot yet observe the employee's performance, current employers might be willing to pay an inventor efficiency wages from the time they update their beliefs on his/her ability to the application date, to prevent key-workers from leaving the firm before completing the patent submission. Note that employers' fear that no other worker in the firm would be able to complete the invention in case the inventor left might be more relevant than the fear that the inventor would disclose his/her knowledge to rival firms, because the latter is often prevented by non-competing agreements.

(b) When inventors take out a patent they reveal their true ability also to rival firms ("public learning") and thus increase the value of their outside options. In this case returns to patents reflect current employers' attempt to prevent poaching from rivals. Patent compensation would timely occur after the patent submission and would permanently shift inventors' wage curve upwards, in the form of either a salary revision or a promotion.

B) Unobserved effort and one-off wage premia.

Moral hazard models are best suited to explain the existence of one-off wage premia. Although employers cannot observe workers' research effort, they can induce effort exertion by conditioning payments to the inventor's performance. In particular, firms may commit to a contract that provides inventors with a one-off bonus any time the worker contributes to a patent application and/or obtains a grant. Since research takes time, firms may find it profitable to raise inventors' effort for a few consecutive years. Thus, dynamic moral hazard models may predict the existence of temporary returns to patents. There are a few theoretical frameworks in which firms might find it 
profitable to pay a premium to inventors to raise their effort.

First, efficiency wage models postulate that workers' effort increases with the size of the rent received (Prendergast, 1999). The idea is that firms encourage employees' good performance by raising the value of the job, which increases the worker's cost of being caught shirking (Krueger and Summers, 1988).

Second, in a relational contract context (see Malcomson (2013) for a review) firms may be willing to share their expected surplus from patents to prevent that inventors perceive their lack of benefits from patenting as unfair and will consequently reduce their future creative effort ${ }^{2}$

Third, repeated interactions may create implicit incentives generating patent premia. In repeatedgames firms build a reputation for rewarding inventors, and employees exert enough effort in research activity with the expectation of the reward. Employers would not renege their obligations (especially if expected rents from patents are high), otherwise they would lose credibility and workers would not innovate anymore.

C) Intrinsic motivation and no patent premia.

Moral hazard models assume that agents are effort averse. However, inventors may invest in research activity just because they enjoy it. According to the cognitive psychology literature, offering workers a monetary reward (extrinsic motivation) to carry out research activity would reduce their intrinsic enjoyment of the task, and thus would lower their propensity to patent. The idea is that when a premium is offered to carry out the research leading to a patent, inventors unconsciously take the compensation rather than their intrinsic desire to invent as the motivation for researching, which, in turn, lowers their effort. Explicit incentives may impair performance even in economic contexts with effort-averse agents. According to Bénabou and Tirole (2003) two conditions are necessary for contingent rewards to crowd-out individuals' intrinsic motivation: (1) the principal (e.g. the firm) must have private information about the agent's (e.g. the inventor's) ability or the task to be performed; (2) the principal must be more willing to reward the agent when the latter is low ability or the task is unattractive. In contrast, when (a) agents learn by

\footnotetext{
${ }^{2}$ In Fehr's and Schmidt's (1999) model the presence of inequity-averse workers induces (selfish) firms to pay a rent in the fear that otherwise workers would retaliate by reducing their effort. In Rabin's (1993) approach firms reward employees to increase their loyalty, fearing that without a compensation workers would feel mistreated and would sabotage them.
} 
doing and (b) their ability to learn increases with talent, rewards enhance productivity also in the long-term. Gneezy and Rustichini (2000) test experimentally the impact of monetary incentives on performance, and find that the effect is detrimental, especially when the reward is low. According to the psychology literature view, pay-for-performance contracts inhibit creativity. In this framework, we should observe no wage variation after a patent submission or grant.

\section{D) Empirical evidence.}

A lot of empirical evidence (not necessarily on the market of inventions) shows that pay-forperformance contracts increase output in settings where performance can be measured. Lazear (2000) finds that a switch from hourly wages to piece-rate pay raises the average productivity of labor; almost half of the increase is due to incentive effects, the rest to an improved selection of workers. Moreover, firms share the productivity gains with their workforce. Since attempting to innovate necessarily involves failures, Manso (2011) argues that the compensation schemes best tailored at motivating innovation should tolerate early failing and reward long-term success. In this light, standard pay-for-performance schemes punishing failures with low rewards and/or termination may, in fact, discourage innovation. Ederer and Manso (2012) suggest that the compensation schemes best aimed at fostering innovation should be long-term, should provide job security and timely feedback on performance, and should also be path dependent (i.e. inventors doing well initially but poorly later should earn less than those who perform badly initially but well later).

In this paper we will verify empirically which of the alternative explanations of the existence of returns to patents is more consistent with our data. We argue that while permanent wage increases are more in line with theories related to ability, one-off premia are more compatible with effort-related models 3

\footnotetext{
${ }^{3}$ Note, however, that observing wage increases for a continuous but limited period of time before submission would be consistent with both theories, as it could be due to: (a) firms starting learning about the true ability of an inventor before the patent application occurs and wanting to retain the employee until he/she completes the work; (b) firms providing a yearly compensation flow to motivate effort for the duration of the research period leading to a patent (dynamic moral hazard model).
} 


\section{The data and descriptive statistics}

We link the employer-employee matched data from the Italian Social Security Institute (Istituto Nazionale di Previdenza Sociale, INPS) to Patstat, the European Patent Office (EPO) Worldwide Patent Statistical Database.

INPS is an administrative dataset following all private-sector workers and firms over time. Being an administrative database, it offers many advantages: it is not affected by systematic measurement errors (see Abowd and Card, 1989) nor by systematic unit- or item- non-response; moreover, earnings are not top-coded, in contrast to wages from employer-employee matched datasets in other countries (e.g. Germany). Like other administrative datasets, its disadvantages are related to the scarcity of the available information at the individual level, which comprises: age, gender, municipality of residence and municipality of birth, work status (blue collar; white collar; manager; other), type of contract (full-time versus part-time) and gross yearly earnings. The information on firms includes: average gross yearly earnings, yearly number of employees, industry, plant location (at the municipality level), date of plant opening and closure.

Patstat contains the universe of patent applications and grants presented at the EPO by any Italian firm since 1978 (when Italian companies started applying at the EPO). The database provides a detailed description of each patent submission, including its title, abstract and technological field, the name and address of residence of all its inventors and applicants (i.e. the firms submitting a patent application and retaining the relative property rights), the dates of application filing, publication and grant obtainment. The EPO releases a new version of Patstat twice a year, but it takes about three years to update its records, thus the most recent data are always incomplete. For this reason we dropped all the patent applications filed in 2007-2009, the last three available years (our Patstat version was released in April 2009). In 2009 the stock of Italian firms' applications at the EPO was about 52,500. Besides dropping the 4,523 applications filed after 2007 (of which only 157 had already been granted), we also excluded those presented before 1987 (amounting to 4, 050, of which 2,685 granted) because we lack of INPS data for that period. After excluding the applications missing relevant information (e.g. applicants' or inventors' names, application dates, etc.) 
our EPO dataset comprises 42,699 patent submissions pertaining to 90,743 firm-inventor-patent records, that is, about 12,000 firms and 33,895 inventors (an average of about 3.5 submissions per firm and 1.5 application per inventor).

Our goal is to match Patstat inventors to INPS workers and firms in order to have the complete work history of all the inventors. Unfortunately, Patstat lacks a firm identifier, like the USPTO dataset (its American counterpart). Thus, we did a challenging work to match Patstat companies and inventors to INPS firms and employees. The difficulties involved in this task include cases of homonymy, spelling errors in the EPO registry, and different filing of business names in the two datasets. The details of our matching procedure are as follows. We merged the datasets in several steps. We first attributed VAT codes to Patstat firms on the basis of the company name and location. To minimize the errors, we verified the code using four alternative datasets (Cebi, Infocamere, INPS, Orbis). We were able to associate a VAT code to 70 percent of Patstat firms (86 percent of which have been assigned a unique VAT code). Then INPS linked Patstat companies to all possible INPS firms that had either the same VAT identifier or the same name and location (at the municipality level). In particular, INPS was able to match 80 percent of the firms to its records (i.e. 9, 748 firms, 19, 022 plants), distributed across all the Italian regions. To determine which of these were correct matches, INPS verified whether the inventors appearing in each patent submission were actually employed in the corresponding applicant firm (from Patstat). To this aim, INPS searched for all the inventor names recorded in its registry of employees, and found 23, 542 employees with the same name of a Patstat inventor (about 70 percent of the total). For more than half of these there was also a correspondence between Patstat's and INPS' employer (at the time of the patent submission). Thus, we were able to match one-third of the universe of inventors employed in an Italian firm with at least one submission to the EPO between 1987 and 2006. The 10,353 unmatchable inventors are either mis-reported, or not employed (e.g. consultants, self-employed or non-formally employed), or employed in an institution not registered with INPS, most likely in the public sector $4^{4}$ In our opinion the majority of the unmatchable inventors are public sector employees (rather than mis-reported and self-employed workers), both because in Italy public-sector research

\footnotetext{
${ }^{4}$ In period analyzed there were two main social security institutions for employees Italy: INPS and INPDAP. The former dealt with most of the private sector and the latter with most of the public sector (including universities).
} 
accounts for more than 40 percent of total research (Istat, 2013) and because INPS deals almost exclusively with the private sector, which may explain why about one-third of the inventors' names are not present in its archives. Thus, we focus on the private sector, and we eliminate the small fraction of the matched inventors employed in the public sector (less than 2 percent of the total). The possibility of exploiting the information on employees improves the precision of our matching procedure with respect to the methods used previously (e.g. the NBER patent database), namely, combining large patent datasets at the firm level on the basis of companies' names and location (see Thoma et al., 2010).

Our employer-employee matched dataset covers the years 1987-2006. It includes the full workhistory of the employees working in any of the patenting firms that INPS was able to match, even if they moved from / to a non-patenting firm. In total it comprises 13,545 inventors working in about 5,000 establishments. The unbalanced panel includes almost 170,000 observations (on average, almost 9,000 inventors per year).

As it is well known, the distribution of patents per inventor is very skewed. In our dataset almost 40 percent of the inventors contributes to just one patent submission in their life, less than 20 percent to two, about 10 percent to three, and just 8 percent of the inventors applies at least 5 times (Figure 1. upper panel). The distribution of granted patents is similar, with 30 percent of the inventors not obtaining any grant within our observational period, and almost one-third being granted just one (Figure $1 \mathrm{~s}$ lower panel). The average number of years for an application to be granted is about 4.4 for the whole period, although the time to obtain a grant decreased in the last decade (see Table 1). Table 2 shows the distribution of patent applications by sector. As expected, patents are mostly concentrated in the industrial sector, especially in terms of inventors (98 percent of the total). The retail sector accounts for 1.8 percent of submissions; artisan businesses, which tend to be smaller and more traditional than the others, hardly apply. Geographically, most of the applications are concentrated in the North of Italy: Lombardy accounts for more than 40 percent of total submissions (see Table 3 and Figure 2). Table 4 shows the descriptive statistics. Inventors' earn slightly more than 40,000 euros per year in the 1987-2006 period average. The great majority of inventors are full-time workers and males; the prevailing work-status is white-collar (60 percent 
of the total). The average employee of our sample is almost 40 years old. On average, each firms has 1.8 plants.

\section{Empirical model and results}

We estimate individual returns to patents with a Mincerian wage function (see Mincer, 1976) augmented with an indicator of patents, run on inventors over the years 1987-2006 5

$$
w_{i j t}=\sum_{k=-K}^{K} \delta_{t-k} \text { Patent }_{i j, t-k}+X_{i j t}^{\prime} \beta+\alpha_{i}+\gamma_{t}+\epsilon_{i j t},
$$

where $w_{i j t}$ is the gross yearly income (including social security contributions, taxes, overtime work, Christmas bonuses) of employee $i$ in firm $j$ in year $t$; Patent is an innovation proxy, $X_{i j t}$ is a vector of individual observable characteristics; $\alpha_{i}$ are worker fixed effects (e.g. ability); $\gamma_{t}$ are year dummies; $\epsilon_{i j t}$ is an error component with zero mean. Errors are always clustered both at the individual and at the firm level (Cameron, Gelbach and Miller, 2011) and always exploit the longitudinal dimension of the data. In what follows we suppress the index $j$ unless we explicitly deal with firm characteristics.

The main objective of this paper is to test whether employees obtain a premium when they contribute to a patent submission, and whether this takes the form of a one-off bonus at the time of invention, in line with the "unobserved effort" theoretical framework, or whether it permanently increases wages, as "unobserved ability" theories would predict. Consistently with this aim, we augment the set of standard Mincerian covariates with Patent, a proxy for innovation. Following a large body of the literature, we measure innovation with patent submissions (see, for instance, Griliches, 1990). In contrast to Toivanen and Väänänen (2012) we use submitted rather than granted patents, for two main reasons. First, because the former are a better and more timely indicator of whether individuals are engaged in research activity (Lotti and Schivardi, 2005). Second, because using submissions instead of grants increases the robustness of our results to endogenous

\footnotetext{
${ }^{5}$ Recall that to ensure that the EPO had the time to examine all the submissions received we restricted our sample to the period 1987-2006. We are thus confident that our sample is only marginally affected by a truncation problem.
} 
mobility (i.e. the bias arising from inventors switching from one firm to another as a consequence of a successful patent). Nevertheless, we also recognize that grants may provide a better quality and a more objective signal on inventors' ability than applications. Therefore, we run a specification of the model in which we distinguish between the submissions that will eventually be granted a patent in our observational period from those that will not (see Section 4.2).

For these reasons, in our main model we define Patent $t_{i j t}$ as a dummy variable equal to one if the employee $i$ contributed to a patent submitted by firm $j$ at time $t$. To discern between oneoff and lasting premia after patenting, we include all the possible forward and backward lags of the patent variable (Patent $_{t-k}$ and Patent $_{t+k}$, with $\left.\mathrm{k}=0,1, \ldots 19\right)$ in all specifications. Testing appropriate restrictions on these parameters will support one or the other theory. In addition, we control for the number of co-authors of each of the patent application (because informal talks with some inventors suggest that firms may pay a fixed premium per submission to be split among all co-authors) and for the number of patent applications that inventors submit each year (to test whether more submissions provide higher premia; Hamermesh and Pfann, 2012).

The other adjusting covariates include a quadratic form of age, work-status (blue-collar, whitecollar, manager or other) and type of contract (full-time or part-time). Ideally, we would need to control for labor market experience and education (see Mincer (1974) and Card, 1999), which are not available. However, this turns out to be a minor issue in our data, because we exploit the longitudinal dimension of the dataset, including workers' fixed effects in all the regressions. Thus, our estimates are consistent even in the presence of unobservable individual time-invariant characteristics, such as personal ability, intelligence, motivation, or education (to the extent that most workers do not improve their education after entering the labor market). Although we recognize that part of these unobservable characteristics may in fact be time-varying, we are confident that our approach eliminates most of this pitfall (Vella, 1998) ${ }^{6}$

\footnotetext{
${ }^{6}$ We do not control for individual-specific time-trends because they would be estimated also on post-treatment variation (Kline, 2012).
} 


\subsection{Main specification}

Tables 5 and Table 6 report the relevant coefficients of equation 1 (the complete set is available on our websites). In Table 5 we progressively enrich the model specifications to test whether our coefficients of interest change as the set of covariates increases and in Table 6 we focus on our benchmark specification to evaluate systematic differences across relevant sub-samples.

The patent proxy we use in Table 5 is a dummy variable equal to one if the individual contributed to a patent application in year $t$. We normalize the first lead $(t-1)$ to zero, so that, all else being equal, the marginal returns to patents at time $t$ with respect to $t$ - 1 is just the coefficient on earnings at $t$. We test six specifications, progressively adding the observable covariates. In the first column, (5.1), we just control for the patent proxies number of co-authors and yearly number of patent submissions. In the second specification we add the time dummies to control for the business cycle, in the third one we include a quadratic form of inventor's age, to proxy human capital accumulation. In the fourth column we control for contract type and work status (white collar, manager, other, versus blue collar) as a proxy for the individual's skills; in specification (5.5) we add some characteristics of the worker's plant, to control for regional and sectoral structural differences in employees' wage compensation (the sectors are: services, handcraft, retail, agriculture; industry is the omitted category). Finally, in our benchmark specification, (5.6), we also include firm's size (namely, the number of employees and the number of plants).

Results show that controlling for the time dummies lowers the patent wage premium, while adding the covariates other than the business cycle has little impact on our coefficients of interest. This implies that the patent premium is correlated to the business cycle, but not so much to the other individual characteristics. To the best of our knowledge, this important result has never been emphasized before. Our preferred specification, (5.6), shows that wages grow by 1 percent in the average of the period before submission, with a small year-on-year increase up to 3 years before the application date and a 3.5 percent premium at $t$-1 with respect to $t$-2. This last result is line with Toivanen and Väänänen (2012), who find that inventors obtain a 1.6 percent premium when their patent application is granted 17 However, once the authors add 6 leads of their patent

\footnotetext{
${ }^{7}$ Note that the authors' results are only partially comparable to ours, as they measure innovation at the time of
} 
variable (over a 9-year-observational period) the premium at time $t$ disappears. In this specification inventors obtain a $4-5$ percent premium in the 4th-6th year after the grant, which appears to be a longer-lasting (possibly permanent) wage increase to the authors. Our dataset allows us to add up to 19 leads and lags of the patent proxy, enabling a more precise estimation of the patent premia dynamics.

The reason why inventors' wages peak at time $t$ - 1 instead of at $t$ (after controlling for individual/firms characteristics) is possibly due to a bureaucratic lag between the time inventors complete an invention (which is when employers reward them) and the firm's application filing date. Indeed, completed inventions must first be analyzed by the firm's legal office, which might take a few months before deciding whether it is worth submitting the patent application to the EPO. Moreover, submissions to the EPO through a national authority might further delay the filing date. Finally, the variables number of co-authors and number of applications per year have the expected sign but are never statistically significant.

Figure 3 (a) shows the wage dynamics corresponding to specification (5.6) ${ }^{8}$ Before submission earnings steadily increase: a formal test always rejects the null hypothesis that returns are equal across the years preceding submission. After submission earnings drop, but they never return to their previous level (we always reject the null hypothesis that Patent $_{i, t}=$ Patent $_{i, t+1}=\ldots$ Patent $t_{i, t+k}$ ): inventors' earnings fall by 1.9 percent with respect to the peak the year the firm submits to the EPO, keep dropping for the two following years, and then remain stable at a level between the initial wage and the peak, possibly because employers update their information on employees' ability. Furthermore, the wage curve is not symmetrical: $k$ years before an invention the premium is always lower than $k$ years after (the difference in the premium size between -k and $\mathrm{k}$ increases with $|k|$ and it amounts to $2-3$ percentage points for $\mathrm{k} \geq 5$ ). More precisely, a formal t-test always rejects the null hypothesis that premia at time $t-k$ are equal to premia at time $t+k$ (for any $k$ ) at standard confidence levels.

The finding that earnings increase for a few years before the application date suggests that

grant while we do it at the time of submission. Moreover, their basic specification does not include leads and lags of the patent variable, while all our regressions do.

${ }^{8}$ Note that we added a constant (equal to the intercept of specification $(56)$ ) to the wage premia reported in the Figure. 
employers are aware of their employees' research progress even before submission, and pay inventors a small yearly premium, either to prevent them from leaving the company or to keep their effort high up to the patent completion. Also the premium increases over time (up to the application date), possibly because the firm's cost of an inventor leaving the company or the need to raise inventors' effort grows as research progresses. Although we find this interpretation convincing, a reader may argue that the wage increase prior to the patent application is a result of inventors' innovative activity or a characteristic of the inventors (or firms) that would have held regardless of whether the innovation took place. This argument would be consistent with the presence of unobserved heterogeneity beyond the individual-specific intercept, due, for instance, to employers learning over time about inventors' true ability or to inventors "learning-by-doing" but not "bypatenting". In this case our estimate of the premium pattern before the application date would be upward biased (although the bias would most likely be a direct positive externality of the patent itself). The reason why we find this argument less convincing than the ones we suggested above is that for it to be true the employers' or employees' learning process should concern only the inventors who are about to patent (between $t-8$ and $t$ ) and not those who have already patented or will do it at another stage (as our sample comprises only inventors). Finally, the argument that inventors' wages would have grown irrespectively of the patenting activity can hardly be reconciled with our other finding that earnings drop after the application date (see also Section 4.3 ) 9

\subsection{Granted versus non-granted patent submissions}

Our dataset enables us to distinguish between the applications that will eventually be granted a patent and those that will not. This could be a relevant distinction because employers might be able to discern ex-ante the most promising submissions and may decide to reward them accordingly (Table 6). Column (6.1) reports the outcome on the whole sample, corresponding to our benchmark specification, (5.6). Results show that although the pattern is similar to the benchmark's, the inventors who contribute to a patent application that will eventually be granted experience a higher wage increase than those who will not obtain a grant (the difference between the two types

\footnotetext{
${ }^{9}$ The only way to reconcile it would be that the patenting activity penalizes inventors, which is in contrast with the economic theory.
} 
of inventions' premia is at least 2 percent large from $t+2$ onwards). Moreover, the pattern between the two is similar before submission occurs, but afterwards it differs: while the earnings of the employees whose invention will not be granted decrease, those who will eventually be granted a patent exhibit a much slower wage decline or even stable earnings (see Figure 3 (b)). A formal test verifying whether the size of premium is the same at time $t$ - $k$ and at time $t+k$ cannot reject the null hypothesis for non-granted applications, whereas it always rejects it for the submissions that will eventually be granted. We also test whether $k$ years from/to submission granted and non-granted premia are the same, and we always reject the null hypothesis that they are. The premium accruing to the submissions not obtaining the grant does not persist after the application is submitted, whereas that benefitting the applications that will be granted first declines and then increases again, consistently with the theories of unobserved ability.

Considering (6.1) the most flexible specification, we also checked our results against various definitions of the sample and against critical assumptions. Our results are robust to restricting the sample to: a) industry, which is the most patent-intensive sector (column (6.2); b) the North of Italy, which is the most patent-intensive area of the country (specification (6.3); and c) the industrial sector in the North (specification (6,4)). In specifications (6,5)-(6,6) we split the sectors on the basis of their patent stock in the period 1987-2006. In particular, we define as "high frequency" the sectors accounting for about three quarters of total patents (namely, the chemical sector, buildings, and mechanics; the pharmaceutical sector is analyzed separately) and as "low frequency" the rest. Results indicate that in both cases the structure of the premia is quite similar to that of the full sample. Finally, in the pharmaceutical industry (column $(6.7)$ ) the number of years preceding submission in which inventors obtain wage increases is greater than the average, probably because in this sector the research process leading to a patent is longer than in other industries.

The causal interpretation of our results relies on the hypothesis that inventors move randomly across firms, otherwise any observed wage increase may just be the consequence of the job change, reflecting, for instance, different bargaining conditions or the price of a different employer-employee match. If workers moved across firms because of patent submissions, our variable of interest would not be exogenous and our estimates would not be consistent. In the absence of an instrumental 
variable the validity of our results relies on three considerations. First, labor mobility in Italy is generally low. In our sample, 70 percent of the inventors does not move across firms in the 19872006 period (i.e. the "stayers"). Second, the share of the inventors who switches firm is 5 percent 1 year after submission, about 10 percent 2 years after and almost 15 percent 3 years after (the table is available upon request). Third, and most importantly in the absence of instruments, we follow Verbeek and Nijman (1992) and test whether our findings are confirmed within the sample of the stayers (column (6.8)). We find that results are qualitatively similar to those reported in column (6.1), although the stayers' premium is higher than that of the full sample (and thus of the movers'). Thus, if anything, after a firm-switch the movers are subject to a wage reduction with respect to what they would have earned had they stayed in the previous company, which attenuates the possible concern that our results are driven by job changes.

Finally, adding to the previous literature, we run a double fixed-effect estimation (see Abowd, Kramarz and Margolis, 1999) to ensure that our outcome is not affected by unobservable variables at the firm level (e.g. firm-specific compensation policies aimed at inventors). The latter might be particularly relevant, as firm-specific heterogeneity has become increasingly important (Card, Heining and Kline, 2013). The variance explained by the firms' unobservable heterogeneity is only 2 percent of the total variance; thus, previous results are confirmed also in this case (specification (6.9)).

Summarizing, the inventors whose submission will not obtain a grant stop receiving a premium after the application date, whereas those who will be granted a patent continue receiving a premium after submission. This result is more in line with the "unobserved ability" framework, whereby employees' wages permanently increase after their ability is revealed, and suggests that employers make a distinction between different inventors' types. We will investigate this hypothesis in the next section.

\subsection{An event study}

An interesting finding of Section 4.2 is that different types of submissions result in a different premia structure. This leads us to explore other dimensions of heterogeneity, besides the quality of patent 
submissions (i.e. those that will be granted a patent versus those that will not). Thus, we will now test whether the quality of inventors' types, which we proxy with the number of patent applications each individual contributes to during her/his entire working life, affects the patent premium (on the grounds that the greater the number of applications, the higher the ability of inventors). The high skewness of the distribution of patents per inventor (see Section 3 ) suggests that some inventors are higher ability than others and thus might be rewarded differently. In particular, it is possible that employers pay higher patent premia to the "star-inventors" than to the employees who contribute just to a few inventions, because the former have proven to be high-ability types and might have acquired more bargaining power. Conversely, the amount of information embodied in the first patents may not be sufficient for the employer to judge whether the inventor is high-ability or just lucky.

The length of our panel enables us to differentiate among the employee types according to the number of patents they submitted in the twenty years we observe, and to measure the premium $k$ years before/after each invention. We use an "event study" framework (see, for instance, Jacobson, LaLonde and Sullivan (1993) or Kline, 2012) to test whether the premium changes in the neighborhood of the main event (i.e. the individual's patent application), by comparing the earnings developments of the employees who submit at time $t$ to the rest of the inventors. To this aim, we reorder the panel in event time. We keep only the inventors who submitted $n$ times between 1987 and 2007, estimating the dynamics of the premium at each invention. This split-sample approach enables us to differentiate the types of inventors on the basis of the number of their inventions.

We now estimate:

$$
w_{i t}=\sum_{n} \sum_{k=-19}^{19} \delta_{n}^{k} E_{n, i t}^{k}+X_{i t}^{\prime} \beta+\alpha_{i}+\gamma_{t}+\epsilon_{i t},
$$

where $E_{n, i t}^{k}$ are a set of dummy variables equal to 1 if the employee $i$ applied for the $n$-th patent (for $\mathrm{n}=1,2,3$, and $n \geq 5$ ) $k$ periods before the current year $t$ (or $k$ periods after, if $k$ is negative), with $k=-19,-18, \ldots, 0,1,2, \ldots 19 . \delta_{n}^{k}$ is the effect of the $n$-th submission on wages $k$ periods away from the application date. Like in equation (1), $X_{i t}$ are the employees' observable time-varying characteristics, $\alpha_{i}$ the worker fixed effects, $\gamma_{t}$ the year dummies and $\epsilon_{i t}$ the error term. 
Table 7 reports the relevant coefficients for the last invention. In the first column we restrict the sample to the employees who submitted only once in the 1987-2006 period. In the second specification we keep the sub-sample of the inventors with just two patent applications, and we report the premia relative to the second submission (although we also control for the first one; the table is available in our website). In the third column the event is the third submission; in the fourth specification it is the fifth, estimated on the sample of the inventors with at least five applications (while controlling for the previous four submissions).

Figure 4 plots over time the $\delta_{n}^{k}$ coefficients of the last submission for each $n$ we tested (with 10 percent confidence intervals). The path of the $\delta$ coefficients for $n=1$ is quite similar to that in Figure 3 (a) until the application date (the difference between the two estimates is below 1 percentage point). However, after submission the two curves differ. The wage development emerging with the event study approach shows a more rapid decline than that estimated with the panel approach: the difference between the two becomes sizable two years after submission (3 percentage point) and increases over time (it widens to 10 percentage points from the seventh year). This pattern suggests that the results observed in Table 5 might be largely driven by the star inventors. Indeed, in column (7.1) the $\delta$ coefficients are estimated on the sample of whom submits just once, whereas in specification (56) they are computed on the whole sample of inventors. To support this intuition we now investigate whether patent premia differ between inventor types. We thus turn to analyze the employees who invent more than once.

Column $(7,2)$ and Figure 4 (b) report the development of the earning increases (in the neighborhood of the second invention) of the inventors who submit twice in their life. Similarly to the previous case, wage premia grow up to time $t$ and decrease after, although earnings remain on a higher level than they were before submission (after 7 years the coefficients are no longer significant). To test whether employers behave differently towards the employees who have already proven to be able to submit a patent, we now compare the size of the premium these individuals obtain at their first and second application and we find that the size of the wage increases is similar (both before and after the application date). Moreover, we compare the premia obtained by these employees the first time to those received by the individuals who submit just once in their life. We 
find that the difference is negligible before the application date (less than 2 percent), but larger afterwards (between 1 and 5 percent in the following 5 years). Thus, even though the employers cannot (obviously) forecast the number of inventions each employee is going to undertake over her/his life, they are able, to some extent, to discern the inventors types ex-ante.

The earnings developments of the employees applying three times differ from the previous cases (after controlling for the previous submissions, all their lags, and the other co-variates reported in equation 2), especially after the submission date (column (7.3) and Figure 4 (c)). In particular, the employees who invent three times earn a permanent wage increase after the application date of the third invention: the $\delta$ coefficients are not statistically different from zero after the third submission, while in specifications $(7,1)-(7,2)$ they were significantly negative both after the first and the second application dates. The premium difference between the first, second and third submission of this group of employees is generally negligible (2 percent or less) before the application date; afterwards the wage-gap gradually increases by a small amount. These results suggest that on average employers start updating their priors on their inventors' ability around the third invention.

In contrast to the previous cases, the inventors with five applications or more continue receiving earning increases after the application date (the $\delta$ coefficients are statistically positive from $t$ onwards; specification (7.4) and Figure 4 (d)), possibly because of the presence of outstanding inventors in this group 10

In summary, our results suggest that employers cannot discern the inventor's type of the employees inventing just once or twice, probably because they are not able to judge whether the patent was the outcome of luck or ability. However, after the third submission they update their priors, recognizing that these inventors are of the high-ability type, and thus provide them with a lasting premium. One of the main contributions of this paper to the literature is the following. While none of the agency theories applies to the whole inventor sample, analyzing specific sub-samples is more revealing: the unobserved ability models are more suited for super-star inventors, while the unobserved effort models are more consistent with the results on low-ability inventors (i.e., with $1-2$ inventions).

\footnotetext{
10 To increase the robustness of our results we also run separate regressions for $n=5,6, \ldots 10$ (not shown here because of the small sample sizes, but available upon request), confirming the previous findings.
} 


\section{Conclusions}

This paper analyzes the impact of patents on inventors' wages, using a unique employer-employee matched dataset on patents and earnings between 1987 and 2006. The richness of our data enables us to add to the previous literature by shedding light on the characteristics of the patent premium. In particular, we are able to test whether a patent application premium exists, and whether it is permanent (as unobserved-ability theories would predict) or temporary (in line with the unobservedeffort literature).

By exploiting the longitudinal dimension of our data, we estimate a Mincerian equation where most of the unobservable components determining the inventors' wages are absorbed by the employees fixed-effects. Applying standard techniques, our results show the presence of an inverted U-shaped profile centered around the time of application. In particular, our estimates indicate that inventors' wages steadily increase before patent applications are submitted to the EPO, peak in the year preceding their filing, and then decrease again.

A few points are worth noticing. First, the finding that earnings peak at $t$ - 1 instead of at $t$ is probably the result of bureaucratic delays between the time the invention really takes place and the time when the EPO registers it. Second, we offer two alternative explanations to why earnings increase up to the time the invention is completed. On the assumption that employers know which of their employees is undertaking (promising) research (which takes time) even before submission, they may pay a temporary premium either to retain their key-workers until they are able to submit the patent application to the EPO, or to ensure that inventors persevere (i.e., exert enough effort) for the whole duration of the project. Third, while the wage developments before submission are quite homogenous among different groups of inventors, afterwards they become heterogeneous. For instance, the inventors who will eventually be granted a patent receive a greater wage increase than those who will not.

To further refine our conclusions we also undertake an event study analysis. Because "events" (i.e. inventions) may occur more than once in each inventor's life, we split the sample on the basis of the total number of patents they submit. We find that the earnings of the inventors contributing 
to at least three submissions increase up to the application date, after which they remain flat, in contrast to what occurs to the workers who invent just once or twice in their lives, whose wages lower immediately after submission. Thus, employers are willing to provide a lasting premium, in line with the unobserved ability theories, only to the employees who have proven to be high-ability types (i.e., on average, the employees who contributed to at least three patent applications). In contrast, the employees who have invented just once or twice do not receive any premium after the application date, probably because the employer is still not sure of whether the invention was due to their ability or just to luck. 


\section{References}

Abowd, John M., and David Card. 1989. "On the Covariance Structure of Earnings and Hours Changes", Econometrica, 57, 411-445.

Abowd, John M., Francis, Kramarz, and David N. Margolis. 1999. "High Wage Workers and High Wage Firms". Econometrica, 67, 251-333.

Arora, Ashish, Marco Ceccagnoli, and Wesley M. Cohen, 2008. "R\&D and the patent premium". International Journal of Industrial Organization, 26, 1153-1179.

Balasubramanian, Natarajan and Jagadeesh Sivadasan. 2011. "What Happens When Firms Patent? New Evidence from U.S. Economic Census Data". The Review of Economics and Statistics, 93, 126-146.

Bénabou, Roland and Jean Tirole. 2003. "Intrinsic and Extrinsic Motivation," Review of Economic Studies, 70, 489-520.

Boldrin, Michele and David K. Levine. 2013. "The Case Against Patents". Journal of Economic Perspectives, 27, 3-22.

Cameron, Colin, Jonah Gelbach, and Douglas Miller. 2011. "Robust Inference with Multi-way Clustering," Journal of Business and Economic Statistics, 29, 238-249.

Card, David. 1999. "The Causal Effect of Education on Earnings", Handbook of labor economics, Vol.30, pp.1801-1863.

Card, David, Jorg Heining, and Patrick Kline. 2013. "Workplace Heterogeneity and the Rise of West German Wage Inequality," Quarterly Journal of Economics, 128, 967-1015.

Eaton, J., and S. Kortum. 1999. "International technology diffusion, theory and measurement". International Economic Review, 40, 537-570.

Ederer, Florian, and Gustavo Manso. 2012. "Is Pay-for-Performance Detrimental to Innovation?," mimeo. 
Farber, Henry, and Robert Gibbons. 1996. "Learning and Wage Dynamics," The Quarterly Journal of Economics, 111, 1007-1047.

Fehr, Ernst, and Klaus M. Schmidt. 1999. "A Theory of Fairness, Competition, and Cooperation", The Quarterly Journal of Economics, 817-868.

Geroski, Paul, Steve Machin and John Van Reenen. 1993. "The Profitability of Innovating Firms," The RAND Journal of Economics, 24, 198-211.

Gneezy, Uri and Aldo Rustichini. 2000. "Pay Enough or Don’t Pay at All," Quarterly Journal of Economics, 115, 791-810.

Griliches, Zvi. 1990. "Patent Statistics as Economic Indicators: A Survey," Journal of Economic Literature, 28, 1661-1707.

Griliches, Zvi, Ariel Pakes and Bronwyn Hall. 1986. "The Value of Patents as Indicators of Inventive Activity," NBER Working Paper no. 2083.

Hall, Bronwyn, Jaffe, Adam, and Manuel Trajtenbergm. 2000. "Market Value and Patent Citations: A First Look," NBER Working Paper no. 7741.

Hamermesh, Daniel, and Gerard Pfann. 2012. "Reputation and Earnings: the Roles of Quality and Quantity in Academe," Economic Inquiry, 50, 1-16.

Jacobson, Louis S., LaLonde, Robert, and Daniel Sullivan. 1993. "Earnings Losses of Displaced Workers," The American Economic Review, 83, 685-709.

Kline, Patrick. 2012. "The Impact of Juvenile Curfew Laws on Arrest of Youth and Adults," The American Law and Economics Review, 14, 44-67.

Krueger, Alan, and Lawrence H. Summers. 1988. "Efficiency Wages and the Inter-Industry Wage Structure," Econometrica, 56, 259-293.

Lazear, Edward P. 1986. "Salaries and Piece Rates," Journal of Business, 59, 405-431. 
Lazear, Edward P. 2000. "Performance Pay and Productivity," The American Economic Review, 90, 1346-1361.

Lerner, Josh and Julie Wulf. 2007. "Innovation and incentives: Evidence from Corporate RD," The Review of Economics and Statistics, 89, 634-644.

Lotti, Francesca, and Fabiano Schivardi. 2005. "Cross-country differences in patent-propensity: a firm-level investigation," Giornale degli economisti, 64, 469-502.

Malcomson, James M. 2013. "Relational Incentive Contracts". In Robert Gibbons and John Roberts (eds.), Handbook of Organizational Economics, Princeton University Press, Princeton, pp. 1014-1065.

Manso, Gustavo. 2011. "Motivating Innovation," The Journal of Finance, 66, 1823-1860.

Mincer, J. 1974. Schooling, Experience and Earnings. New York: Columbia University Press.

Moser, Petra. 2013. "Patents and Innovation: Evidence from Economic History". Journal of Economic Perspectives, 27, 23-44.

Prendergast, Canice. 1999. "The provision of incentives in firms". Journal of Economics Literature, 37, 7-63.

Rabin, Matthew. 1993. "Incorporating Fairness into Game Theory and Economics," The American Economic Review, 83, 1281-1302.

Thoma, Grid, Salvatore Torrisi, Alfonso Gambardella, Dominique Guellec, Bronwyn H. Hall and Dietmar Harhoff. 2010. "Harmonizing and Combining Large Datasets - An Application to Firm-level Patent and Account Data," NBER Working Paper no. 15851.

Toivanen, Otto, and Lotta Väänänen. 2012. "Returns to Inventors," The Review of Economics and Statistics 94, 1173-1190.

Van Reenen, John. 1996. "The Creation and Capture of Rents: Wages and Innovation in a Panel of U.K. Companies," The Quarterly Journal of Economics, 111, 195-226. 
Vella, F. 1998. "Estimating Models with Sample Selection Bias: A Survey" Journal of Human Resources, 33, 88-126.

Verbeek, Marno, and Theo Nijman. 1992. "Testing for Selectivity Bias in Panel Data Models," International Economic Review, 33, 681-703. 
Figure 1: Patent applications per inventor (upper panel) and patent grants per inventor (lower panel)
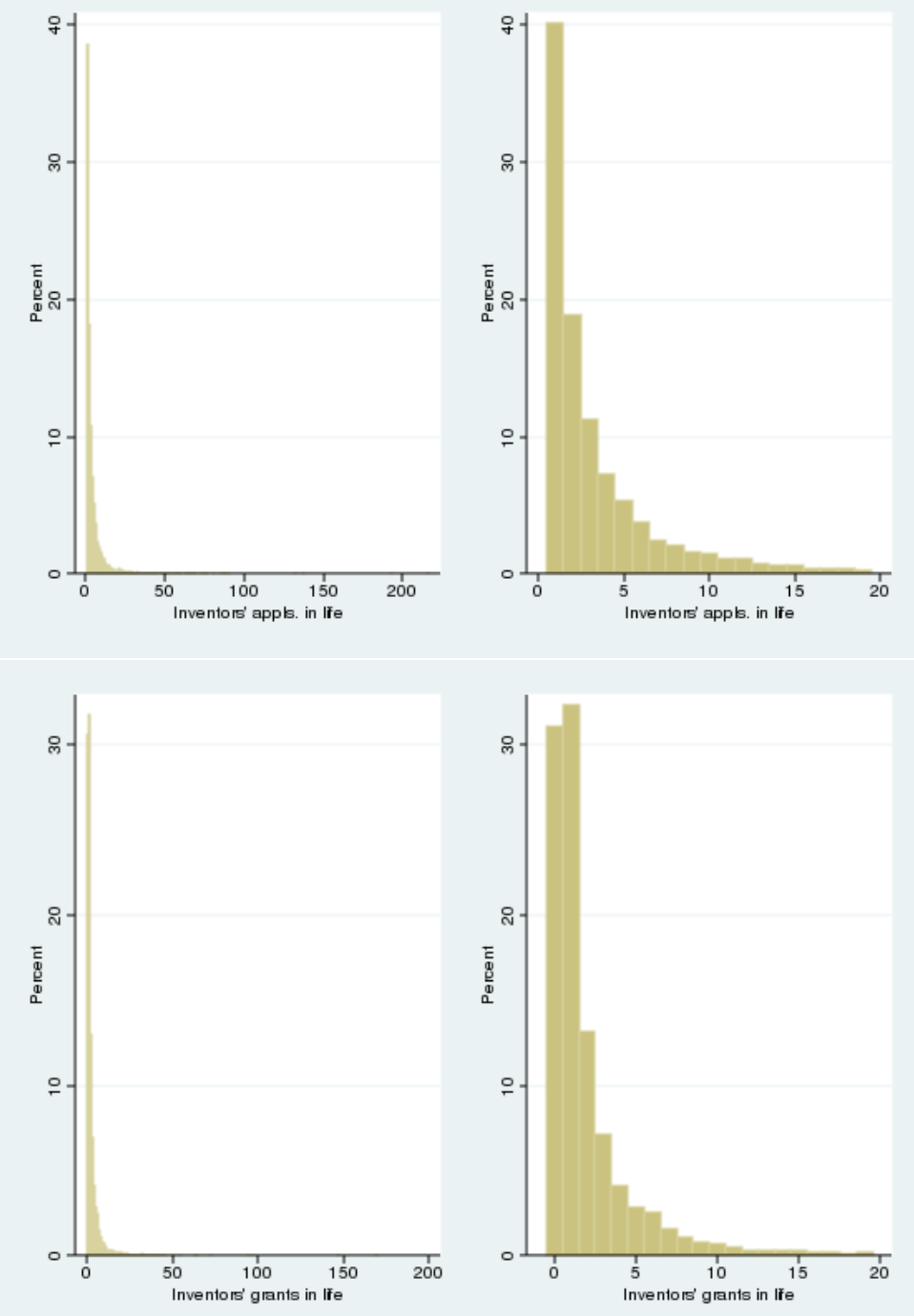
Table 1: Number of years from application to grant

\begin{tabular}{l|lll|llll}
\hline & \multicolumn{5}{|c}{ Applications } & \multicolumn{5}{c}{ Years to grant } \\
Year & Total & Granted & Not yet granted & Min & Mean & Median & Max \\
\hline 1987 & 791 & 585 & 206 & 2 & 4.846154 & 5 & 16 \\
1988 & 850 & 617 & 233 & 2 & 4.560778 & 4 & 9 \\
1989 & 979 & 661 & 318 & 2 & 4.503782 & 4 & 16 \\
1990 & 1198 & 832 & 366 & 2 & 4.497596 & 4 & 14 \\
1991 & 1111 & 756 & 355 & 2 & 4.367725 & 4 & 11 \\
1992 & 1344 & 839 & 505 & 2 & 4.296782 & 4 & 14 \\
1993 & 1307 & 968 & 339 & 1 & 4.532025 & 4 & 14 \\
1994 & 1256 & 905 & 351 & 1 & 4.701657 & 4 & 13 \\
1995 & 1401 & 1034 & 367 & 1 & 5.029014 & 5 & 14 \\
1996 & 1572 & 1177 & 395 & 1 & 5.169074 & 5 & 12 \\
1997 & 1698 & 1163 & 535 & 1 & 5.28031 & 5 & 12 \\
1998 & 1824 & 1174 & 650 & 1 & 5.261499 & 5 & 11 \\
1999 & 1800 & 1162 & 638 & 2 & 5.08864 & 5 & 10 \\
2000 & 2068 & 1267 & 801 & 2 & 4.797948 & 4 & 9 \\
2001 & 2373 & 1365 & 1008 & 1 & 4.394139 & 4 & 8 \\
2002 & 2785 & 1530 & 1255 & 1 & 3.983006 & 4 & 7 \\
2003 & 3035 & 1434 & 1601 & 1 & 3.864017 & 4 & 6 \\
2004 & 3084 & 1339 & 1745 & 1 & 3.275579 & 3 & 5 \\
2005 & 3025 & 902 & 2123 & 1 & 2.978936 & 3 & 4 \\
2006 & 3195 & 613 & 2582 & 1 & 2.401305 & 2 & 3
\end{tabular}

Table 2: Distribution of patent applications by sector (percent)

\begin{tabular}{l|lll}
\hline & $\begin{array}{l}\text { Applications } \\
\text { Sector }\end{array}$ & $\begin{array}{l}\text { Inventors } \\
(2.1)\end{array}$ & $\begin{array}{l}\text { Applicants } \\
(2.3)\end{array}$ \\
\hline Industry & 97.3 & 98.0 & 94.9 \\
Services & 0.4 & 0.2 & 0.1 \\
Handcraft & 0.3 & 0.1 & 0.6 \\
Agriculture and Fishing & 0.2 & 0.1 & 0.2 \\
Retail & 1.8 & 1.6 & 4.1 \\
\hline Total & 100.0 & 100.0 & 100.0
\end{tabular}


Table 3: Distribution of patent applications by region (percent)

\begin{tabular}{l|lll}
\hline & Applications & Inventors & Applicants \\
Region & $(3.1)$ & $(3.2)$ & $(3.3)$ \\
\hline ABRUZZO & 1.2 & 1.1 & 0.9 \\
AOSTA VALLEY & 0.2 & 0.1 & 0.2 \\
APULIA & 0.4 & 0.4 & 0.8 \\
BASILICATA & 0.3 & 0.2 & 0.2 \\
CALABRIA & 0.1 & 0.0 & 0.1 \\
CAMPANIA & 0.7 & 0.9 & 1.4 \\
EMILIA-ROMAGNA & 11.8 & 12.4 & 16.0 \\
FRIULI-VENEZIA GIULIA & 5.1 & 4.1 & 3.3 \\
LAZIO & 4.7 & 6.2 & 4.6 \\
LIGURIA & 2.1 & 2.7 & 2.2 \\
LOMBARDY & 41.1 & 38.6 & 35.1 \\
MARCHE & 2.0 & 1.9 & 2.7 \\
MOLISE & 0.2 & 0.1 & 0.1 \\
PIEDMONT & 15.3 & 17.0 & 13.0 \\
SARDINIA & 0.2 & 0.0 & 0.1 \\
SICILY & 2.0 & 1.5 & 0.4 \\
TRENTINO-ALTO ADIGE / SUDTIROL & 0.9 & 0.7 & 1.3 \\
TUSCANY & 4.7 & 4.9 & 4.5 \\
UMBRIA & 0.5 & 0.3 & 0.7 \\
VENETO & 6.7 & 7.2 & 12.6 \\
\hline
\end{tabular}


Figure 2: Distribution of patent applications by region

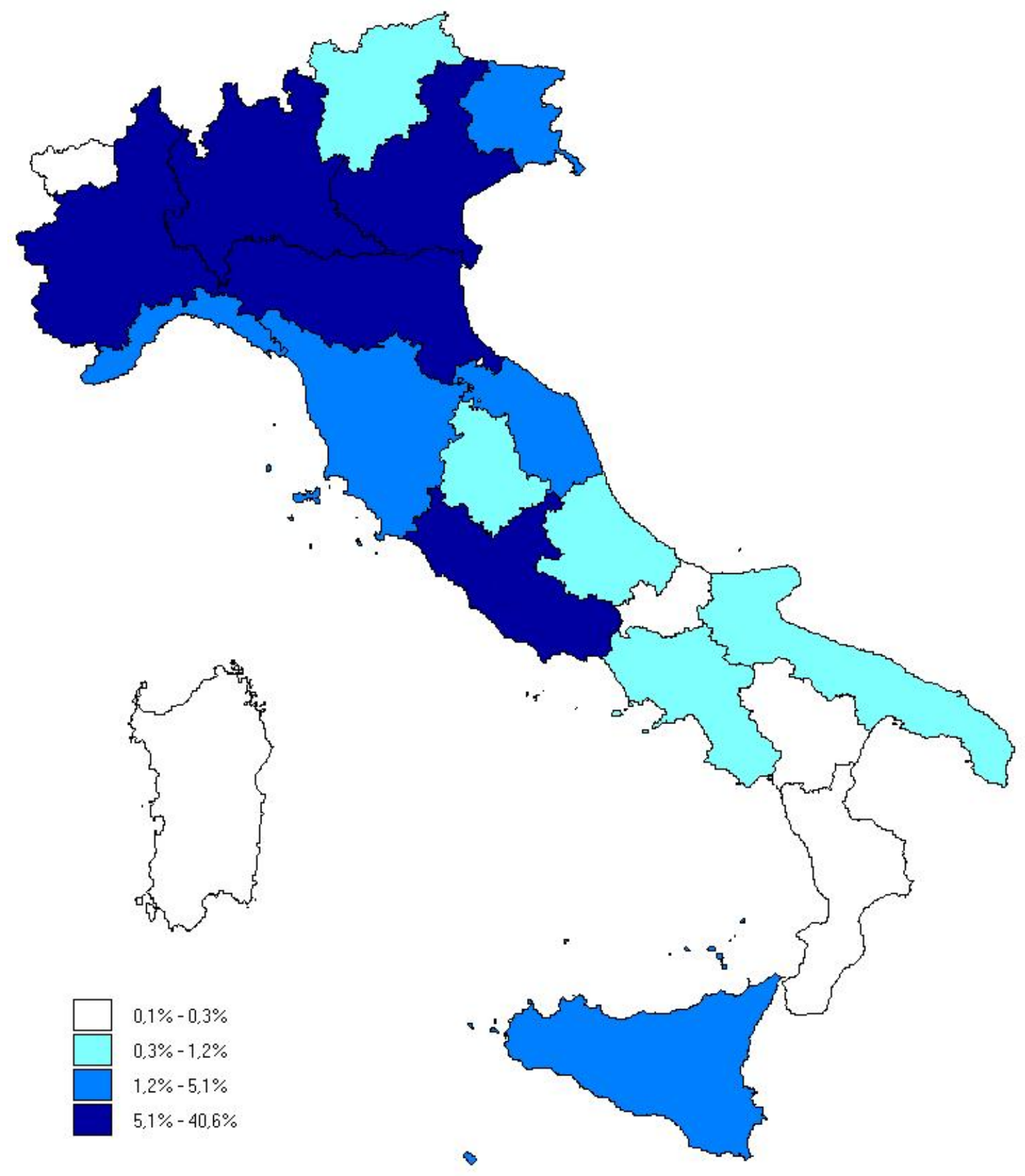


Table 4: Descriptive statistics

\begin{tabular}{l|ll}
\hline Variable & Mean & S.D. \\
\hline Yearly wage & 40924.9 & 34009.0 \\
Female & 0.1 & 0.3 \\
Age & 39.8 & 9.2 \\
Blue collar & 0.0 & 0.2 \\
White collar & 0.6 & 0.5 \\
Manager & 0.0 & 0.1 \\
Other work status & 0.3 & 0.5 \\
Full-time & 1.0 & 0.1 \\
& & \\
No. plants per firm & 1.6 & 2.6 \\
\hline No. obs. & 160,217 &
\end{tabular}


Table 5: Inventors' returns to patents

\begin{tabular}{|c|c|c|c|c|c|c|}
\hline Variables & $(5.1)$ & $(5.2)$ & $(5.3)$ & $(5.4)$ & $(5.5)$ & $(5.6)$ \\
\hline No. inventors per submis. & $-0.006^{* * *}$ & -0.002 & -0.002 & -0.003 & -0.003 & -0.003 \\
\hline Inventors' appls. per year & $-0.021 * * *$ & -0.002 & 0.003 & 0.002 & 0.002 & 0.002 \\
\hline Year submis.t$\cdot-8$ & $-0.191 * * *$ & $-0.106 * * *$ & $-0.103 * * *$ & $-0.100 * * *$ & $-0.100 * * *$ & $-0.100 * * *$ \\
\hline Year submis.t-7 & $-0.169 * * *$ & $-0.097 * * *$ & $-0.095 * * *$ & $-0.093 * * *$ & $-0.093 * * *$ & $-0.093 * * *$ \\
\hline Year submis.t-6 & $-0.155^{* * *}$ & $-0.092 * * *$ & $-0.091 * * *$ & $-0.088 * * *$ & $-0.088 * * *$ & $-0.088 * * *$ \\
\hline Year submis.t-5 & $-0.136 * * *$ & $-0.085 * * *$ & $-0.084 * * *$ & $-0.082 * * *$ & $-0.082 * * *$ & $-0.082 * * *$ \\
\hline Year submis.t-4 & $-0.118^{* * *}$ & $-0.076 * * *$ & $-0.075 * * *$ & $-0.073 * * *$ & $-0.073 * * *$ & $-0.073 * * *$ \\
\hline Year submis.t-3 & $-0.097 * * *$ & $-0.065 * * *$ & $-0.064 * * *$ & $-0.063 * * *$ & $-0.063 * * *$ & $-0.063 * * *$ \\
\hline Year submis.t-2 & $-0.053 * * *$ & $-0.036 * * *$ & $-0.035 * * *$ & $-0.035 * * *$ & $-0.035 * * *$ & $-0.035 * * *$ \\
\hline Year submis.t & $0.046^{* * *}$ & -0.014 & $-0.021 * *$ & $-0.020 * *$ & $-0.020 * *$ & $-0.019 * *$ \\
\hline Year submis. $t+1$ & -0.003 & $-0.034 * * *$ & $-0.035 * * *$ & $-0.035 * * *$ & $-0.035 * * *$ & $-0.034 * * *$ \\
\hline Year submis. $t+2$ & $-0.019 * * *$ & $-0.058 * * *$ & $-0.057 * * *$ & $-0.057 * * *$ & $-0.057 * * *$ & $-0.057 * * *$ \\
\hline Year submis. $t+3$ & $-0.024 * * *$ & $-0.069 * * *$ & $-0.065 * * *$ & $-0.065 * * *$ & $-0.065 * * *$ & $-0.065 * * *$ \\
\hline Year submis. $t+4$ & $-0.021 * * *$ & $-0.074 * * *$ & $-0.066 * * *$ & $-0.066 * * *$ & $-0.066^{* * *}$ & $-0.065 * * *$ \\
\hline Year submis. $t+5$ & $-0.030 * * *$ & $-0.085 * * *$ & $-0.072 * * *$ & $-0.072^{* * *}$ & $-0.073 * * *$ & $-0.072 * * *$ \\
\hline Year submis.t+6 & $-0.031 * * *$ & $-0.089 * * *$ & $-0.072 * * *$ & $-0.072 * * *$ & $-0.072 * * *$ & $-0.071 * * *$ \\
\hline Year submis. $t+7$ & $-0.024 * * *$ & $-0.087 * * *$ & $-0.065 * * *$ & $-0.064 * * *$ & $-0.064 * * *$ & $-0.064 * * *$ \\
\hline Year submis. $t+8$ & $-0.022 * *$ & $-0.097 * * *$ & $-0.069 * * *$ & $-0.067 * * *$ & $-0.067 * * *$ & $-0.067 * * *$ \\
\hline Individual-FE & YES & YES & YES & YES & YES & YES \\
\hline Time dummies & $\mathrm{NO}$ & YES & YES & YES & YES & YES \\
\hline Age & $\mathrm{NO}$ & $\mathrm{NO}$ & YES & YES & YES & YES \\
\hline Job characteristics & $\mathrm{NO}$ & $\mathrm{NO}$ & $\mathrm{NO}$ & YES & YES & YES \\
\hline Sector; Region & $\mathrm{NO}$ & $\mathrm{NO}$ & $\mathrm{NO}$ & $\mathrm{NO}$ & YES & YES \\
\hline Firm size; no. plants & $\mathrm{NO}$ & NO & $\mathrm{NO}$ & NO & NO & YES \\
\hline No. obs. & 160,217 & 160,217 & 160,217 & 160,217 & 160,217 & 160,217 \\
\hline
\end{tabular}

Notes: The dependent variable is the yearly wage. Regressions are run on the inventors' sample and use a fixed effect estimation method. Standard errors are always clustered both at the firm and at the employee level. Patent wage premia are computed with respect to the year before submission at EPO. All specifications control for: 19 forward-lags and 19 backward lags of the patent variable (available upon request). Variables denoted with ${ }^{*}(* *)[* * *]$ indicate statistical significance at the 10 (5) [1] percent level. 


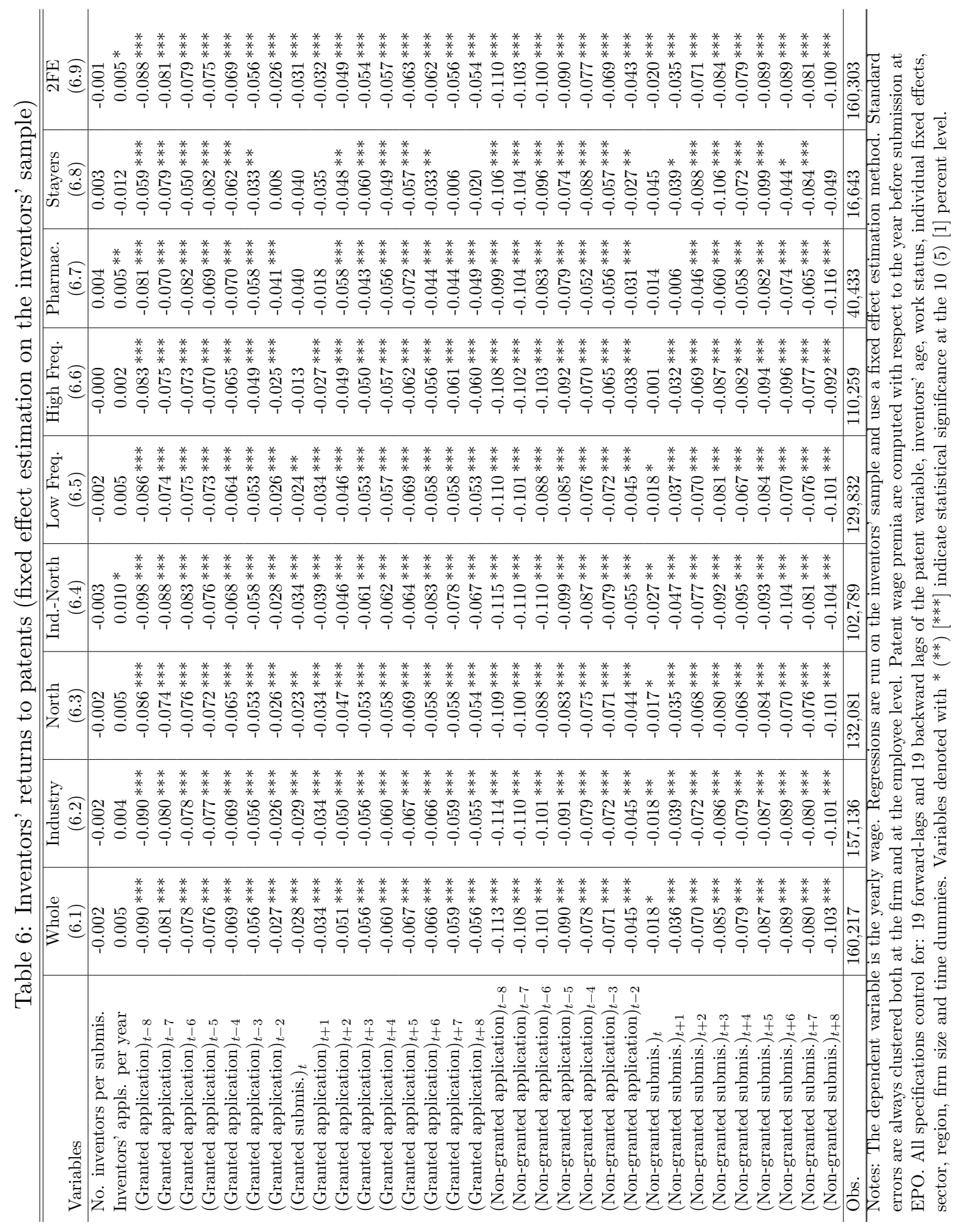


Figure 3: Inventors' earnings at the time of application

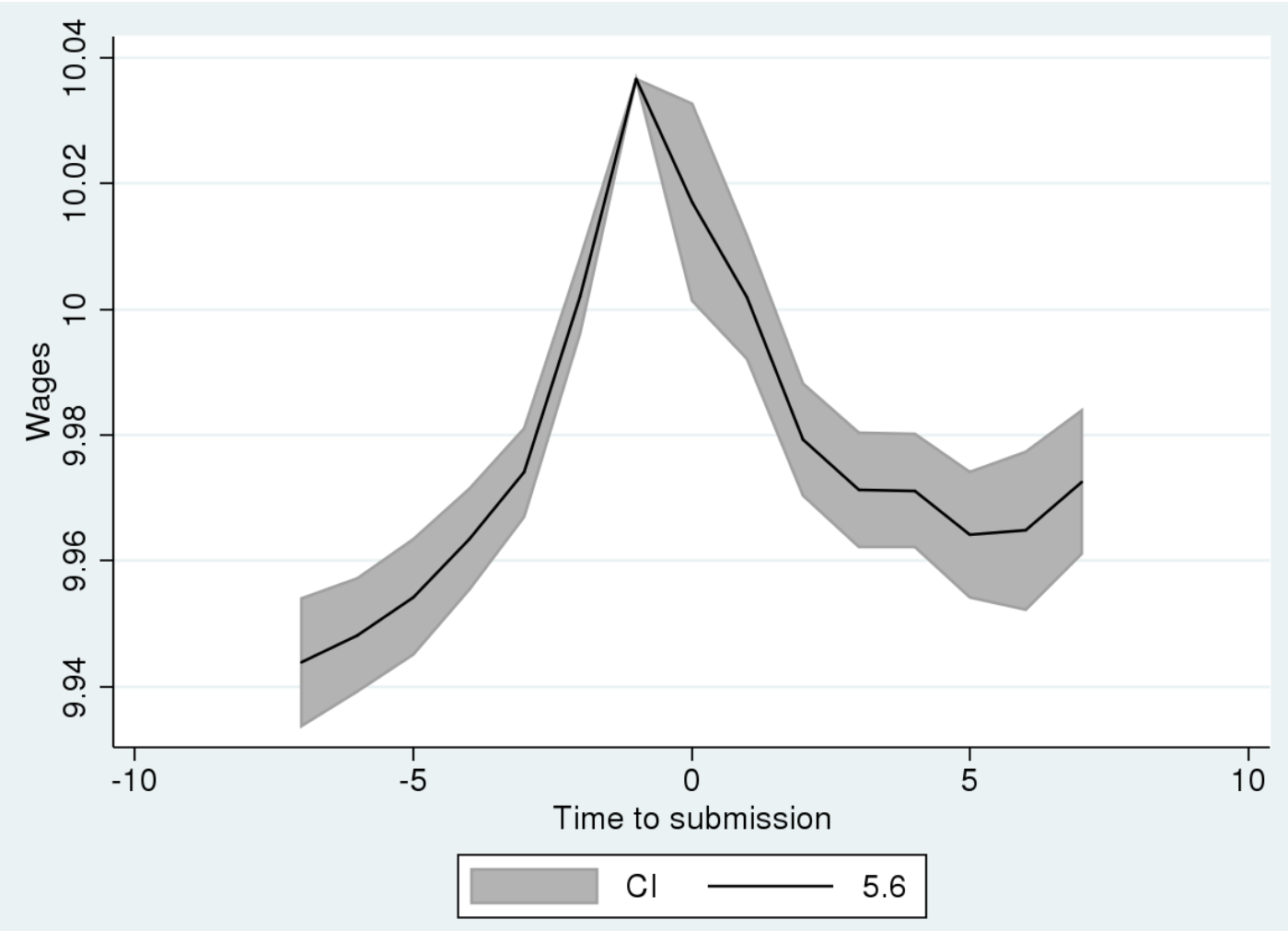

(a) Inventors' earnings at the time of application (Table 5, column (5.6))
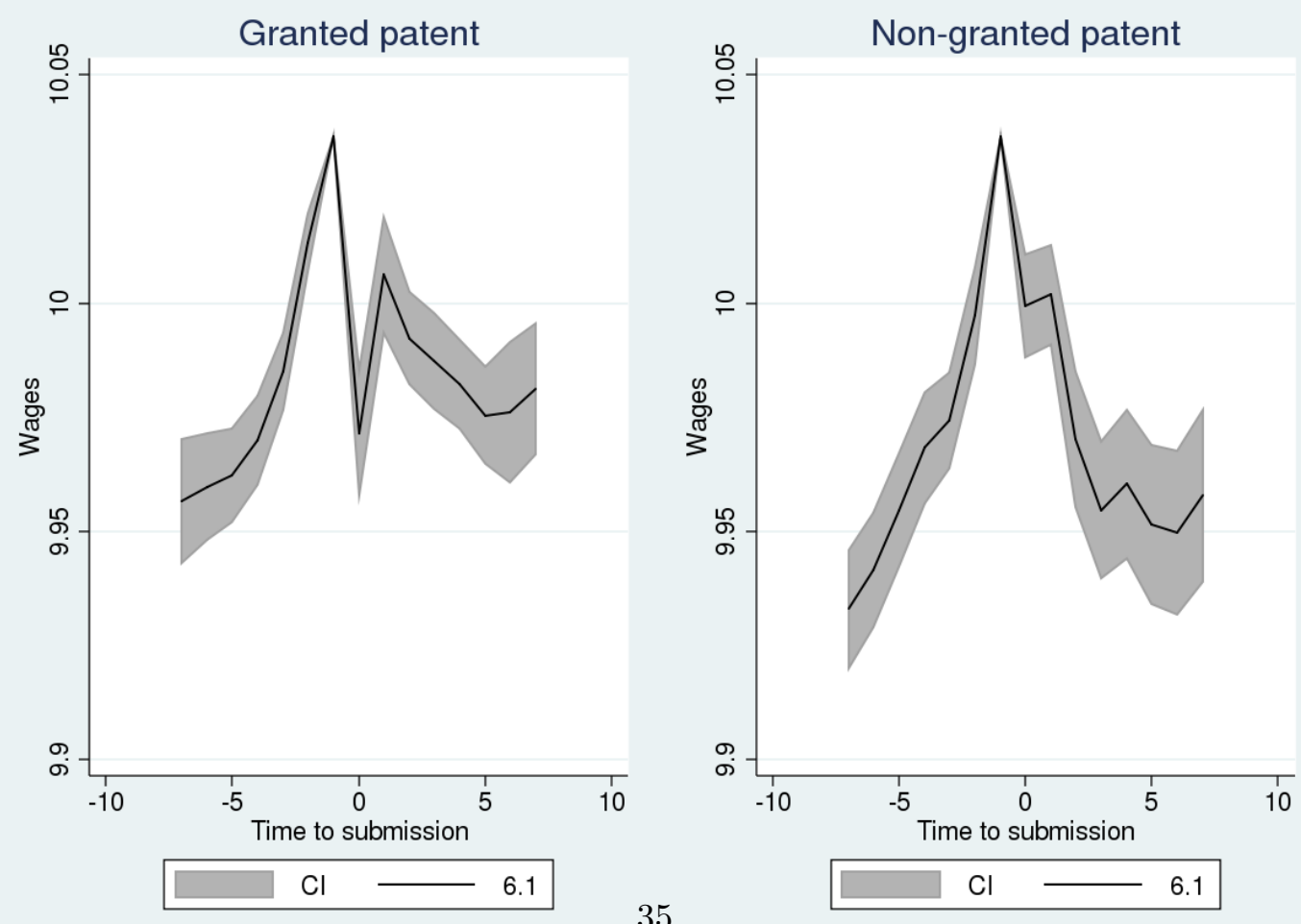

(b) Inventors' earnings at the time of application (granted patents (b); non-granted patents (c)) 
Table 7: Inventors' returns to patents by number of invention: Event studies

\begin{tabular}{|c|c|c|c|c|}
\hline Variables & $\begin{array}{l}\mathrm{n}=1 \\
(7.1)\end{array}$ & $\begin{array}{l}\mathrm{n}=2 \\
(7.2)\end{array}$ & $\begin{array}{l}\mathrm{n}=3 \\
(7.3)\end{array}$ & $\begin{array}{l}n \geq 5 \\
(7.4)\end{array}$ \\
\hline Year submis.t-8 & $-0.106^{* * *}$ & $-0.119 * * *$ & $-0.096 * * *$ & $-0.107 * * *$ \\
\hline Year submis. $t-7$ & $-0.091 * * *$ & $-0.109 * * *$ & $-0.094 * * *$ & $-0.108 * * *$ \\
\hline Year submis. $t-6$ & $-0.090 * * *$ & $-0.107 * * *$ & $-0.085 * * *$ & $-0.113 * * *$ \\
\hline Year submis.t-5 & $-0.092 * * *$ & $-0.097 * * *$ & $-0.064 * *$ & $-0.090 * * *$ \\
\hline Year submis.t-4 & $-0.078 * * *$ & $-0.068 * * *$ & $-0.078 * * *$ & $-0.089 * * *$ \\
\hline Year submis.t-3 & $-0.073 * * *$ & $-0.056 * * *$ & $-0.051 * * *$ & $-0.077 * * *$ \\
\hline Year submis.t-2 & $-0.030 * * *$ & $-0.033 * * *$ & $-0.056 * * *$ & $-0.038 * * *$ \\
\hline Year submis.t & -0.005 & -0.019 & -0.025 & -0.006 \\
\hline Year submis. $t+1$ & $-0.050 * * *$ & $-0.050 * * *$ & -0.007 & $0.030 * * *$ \\
\hline Year submis. $t+2$ & $-0.087 * * *$ & $-0.061 * * *$ & -0.027 & $0.013^{* * *}$ \\
\hline Year submis. $t+3$ & $-0.108 * * *$ & $-0.104 * * *$ & -0.090 & $0.042^{* * *}$ \\
\hline Year submis. $t+4$ & $-0.118^{* * *}$ & $-0.064 * *$ & $-0.134 * *$ & $0.014^{* *}$ \\
\hline Year submis. $t+5$ & $-0.140 * * *$ & $-0.079 * *$ & -0.037 & $0.045 * *$ \\
\hline Year submis.t+6 & $-0.164^{* * *}$ & $-0.146 * * *$ & -0.006 & $0.081^{* * *}$ \\
\hline Year submis. $t+7$ & $-0.161^{* * *}$ & -0.062 & $-0.225^{*}$ & 0.101 \\
\hline Year submis. $t+8$ & $-0.164^{* * *}$ & -0.023 & -0.546 & 0.078 \\
\hline No. inventors per submis. & $-0.010 * *$ & 0.002 & -0.008 & 0.002 \\
\hline $\begin{array}{l}\text { Inventors' appls. per year } \\
\text { Age }\end{array}$ & $0.049 * * *$ & -0.022 & 0.021 & 0.012 \\
\hline No. obs. & 58,722 & 29,255 & 17,871 & 42,584 \\
\hline
\end{tabular}

Notes: The dependent variable is the yearly wage. Regressions are run on the inventors' sample and use a fixed effect estimation method. Standard errors are always clustered both at the firm and at the employee level. Patent wage premia are computed with respect to the year before submission at EPO. All specifications control for: 19 forward-lags and 19 backward lags of the patent variable (available upon request). Variables denoted with $*(* *)[* * *]$ indicate statistical significance at the 10 (5) [1] percent level. 
Figure 4: Inventors' earnings in the neighborhood of submission

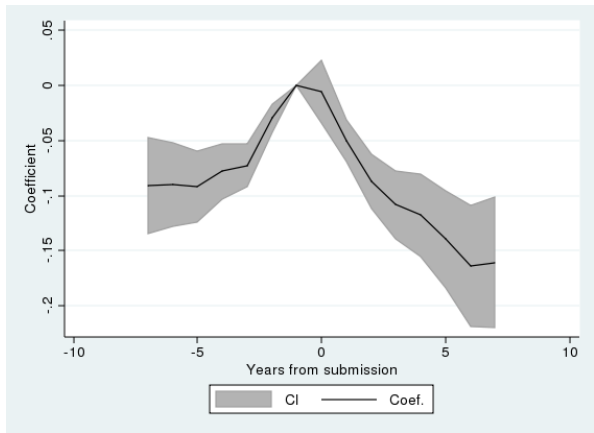

(a) $n=1$

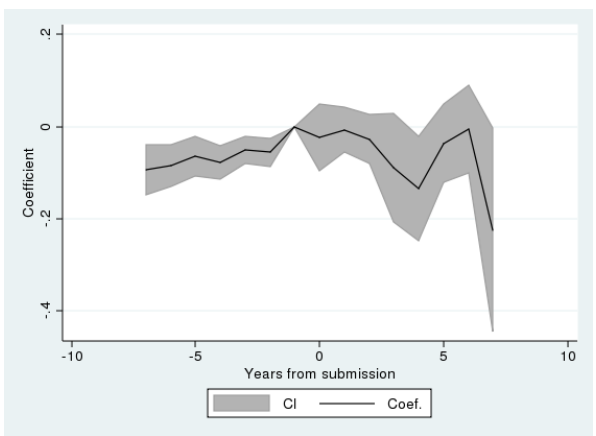

(c) $\mathrm{n}=3$

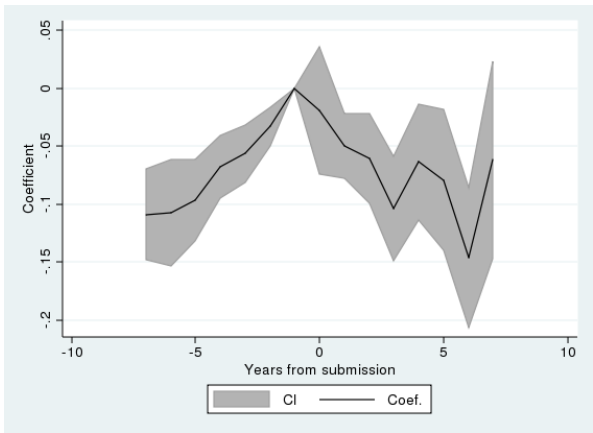

(b) $n=2$

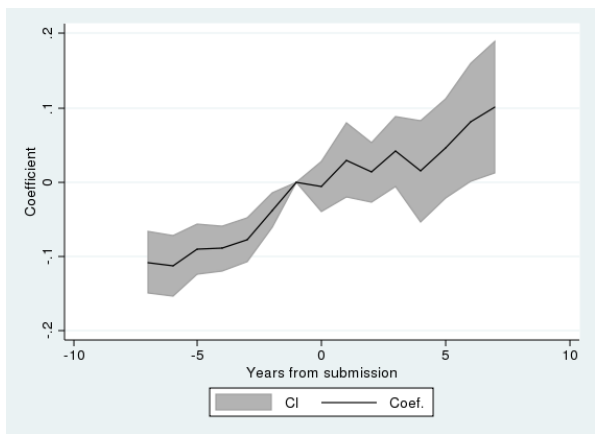

(d) $n>5$ 